\title{
Assessing risk and emotional disturbance using the CORE-OM and HoNOS outcome measures at the interface between primary and secondary mental healthcare
}

\author{
AIMS AND METHOD \\ There is interest in how outcome \\ measures routinely used in mental \\ health settings compare with each \\ other in assessing risk and emotional \\ disturbance. The relation between \\ the Clinical Outcomes in Routine \\ Evaluation - Outcome Measure \\ (CORE-OM), a client-completed \\ measure, and the Health of the \\ Nation Outcome Scale (HoNOS), a
}

\author{
clinician-completed measure, was \\ explored using data from 297 clients \\ referred to secondary services by a \\ primary care mental health liaison \\ team.
RESULTS
The correlation between CORE-OM factor analyses revealing overlap between the measures in assessing \\ and HoNOS was 0.50 , with cluster and
}

\author{
risk to self and others and general \\ emotional issues.
CLINICAL IMPLICATIONS
Although the measures are typically used in different settings, the overlap suggests that both might be useful in any setting where assessment for mental health problems and risk is \\ needed.
}

Routine outcome measurement has been increasingly advocated for mental health and psychological services, with the Department of Health committed to the implementation of outcome measures in routine practice in mental health services (National Institute for Mental Health in England, 2002, 2004). This momentum has been evidenced by a report (Fonagy et al, 2004) building on the work of an expert advisory group on mental health outcomes, which concludes that the Health of the Nation Outcome Scale (HoNOS; Wing et al, 1998) 'could provide a developmental anchor setting the minimum domains to be covered for the relevant population' (Fonagy et al, 2004: p. 6). The report also states that 'Trust[s] should also explore the use of other clinician rated and self report measures, including quality of life measures, so as to ensure that relevant domains can be appropriately measured across the populations served' (Fonagy et al, 2004: p. 6).

These statements reflect a strategy whereby the appropriateness and utility of bona fide outcome measures should be investigated but that they need to be empirically anchored against HoNOS. Although no single measure could possibly capture the whole range of presenting problems and outcomes across mental health, establishing evidence of the relationship between measures and the extent to which they capture common and unique aspects of experience is important. This would add to validation evidence for the measures and clarify the extent to which they are useful for particular populations and in particular service settings. Accordingly, we focused on the HoNOS and a widely used selfreport measure, the Clinical Outcomes in Routine Evaluation - Outcome Measure (CORE-OM; Barkham et al, 2001, 2005; Evans et al, 2002). Interestingly, each has been advocated for use at different ends of the severity range. Both measures can be used to assess various aspects of risk of self-harm or harm to others.

The HoNOS is advocated as suitable for use at the severe end of the spectrum to provide a practitioner- completed assessment across 12 domains, divided into four subgroups. Risk to self and others is assessed by two items in subgroup A (behavioural problems). This measure has derived support from some reviewers (e.g. Rees et al, 2004) and been criticised by others (e.g. Audin et al, 2001). The empirical relationship between HoNOS and other outcome measures has been investigated and significant associations have been reported. Orrell et al (1999) established significant correlations between HoNOS and a battery of six outcome measures on a sample of 100 patients: 0.59 for the Social Behaviour Scale (Wykes \& Sturt, 1986), 0.51 for the Location of Community Support Scale (Kazarian \& Joseph, 1994), 0.40 for the Brief Psychiatric Rating Scale (BPRS; Overall \& Gorham, 1962), -0.40 for the Global Assessment Scale (GAS; Endicott et al, 1976), 0.36 for the General Health Questionnaire (Goldberg, 1978) and -0.33 for the Medical Outcomes Study Short Form-36 (Ware \& Sherbourne, 1990). McClelland et al (1998) reported correlations on presentation to the service between HoNOS and GAS of 0.49 and with the BPRS of 0.44 .

The CORE-OM is a 34-item self-report measure tapping four domains, including a risk sub-scale assessing risk to others (two items) and risk to self (four items). It has been widely used to measure emotional disturbance in service settings delivering psychological interventions in primary and secondary care (Barkham et al, 2005). Its relationship to other measures, including the Beck Depression Inventory (Beck \& Steer, 1993), has been explored in large-scale studies (e.g. Leach et al, 2005).

Our study assesses the empirical relationship between these measures and their potential to complement each other across a range of settings.

\section{Method}

Data were collected as part of routine service delivery for clients referred to the Primary Care Liaison, Assessment 


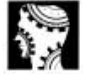

original papers
Treatment and Training (PLATT) team of a large mental health National Health Service (NHS) trust. This multidisciplinary team provides a service within two primary care trusts and serves a population of 330000 . The PLATT team receives 60 adult referrals a week, mainly from general practice, and provides an assessment filter for all mental health services in one locality. All those referred routinely complete the CORE-OM at assessment. For those receiving therapy within the PLATT service, the CORE-OM is also used before therapy and at discharge. For the first 6 months of the service, assessors completed HoNOS ratings of people assessed as requiring help from community mental health or psychiatry services.

Data for this study come from a service evaluation database for 1497 persons referred between October 2001 and March 2003. Of these, there were complete data for 1297 clients on CORE-OM and for 507 clients on HoNOS, with 315 clients having complete data for both measures. For some clients, CORE-OM and HoNOS were completed at different stages of therapy, so the study focused on 297 clients (175 women and 122 men) for whom the measures had been completed at assessment and within 30 days of each other. One client with an extreme outlying HoNOS total score of 37 was excluded from further analysis, leaving 296 clients in the study sample, whose HoNOS scores ranged from 0 to 25 ( mean=9.03, s.d. $=4.27$, median $=9.00$ ). The CORE $-O M$ scores ranged from 0.15 to 3.76 ( mean $=2.24$, s.d. $=0.69$, median=2.28), with 274 clients $(93 \%)$ scoring above the CORE-OM clinical cut-offs of 1.29 (female) and 1.19 (male), and 109 (37\%) scoring above the 'severe' cut-off of 2.50 (see Barkham et al, 2001). The excluded client scored 2.93 on the CORE-OM.

Those included in the study sample $(n=296)$ differed from those not included $(n=1000)$ in CORE-OM score ( mean $=2.24$, s.d. $=0.69$, for sample; mean $=2.08$, s.d. $=0.76$, for non-sample; $t=3.28$, d.f. $=1294, P=0.001$ ), but not in age (mean $=37.5$, s.d. $=12.4$, for sample; mean $=36.9$, s.d. $=11.8$, for non-sample; $t=0.71$, d.f. $=1294, P=0.48)$ or gender $(60 \%$ females in sample, $62 \%$ in non-sample; $\chi^{2}=0.86$, d.f. $=1, P=0.36$ ). The difference in CORE-OM mean scores reflects the fact that HoNOS was completed only for individuals assessed as suitable for referral to psychiatric or community mental health team services.

The relation between the two measures was explored using Pearson product-moment correlations to compare total and sub-scale scores. At the item level, hierarchical cluster analysis (Ward's method) and maximum likelihood factor analysis (with oblique rotation) were both carried out, all analyses being performed using the Statistical Package for the Social Sciences, version 12.0

\section{Results}

The correlation between CORE-OM overall score and HoNOS total score was $0.50(P<0.001)$, the scales thus sharing $50 \%$ of the variance (Ozer, 1985), with CORE-OM correlating most highly with the HoNOS sub-scales A (behavioural problems; $r=0.40$ ) and $D$ (social problems; $r=0.39$ ), with a slightly smaller correlation with the $C$ subscale (symptomatic; $r=0.34$ ) and an effectively zero correlation with the B sub-scale (impairment; $r=0.05$ ). The same pattern is apparent for the CORE-OM risk subscale, which had correlations of 0.51 with the HoNOS total score, 0.57 with the A sub-scale, 0.39 with the $D$ sub-scale, 0.22 with the $C$ sub-scale and 0.02 with the $B$ sub-scale.

Table 1 summarises the results of the hierarchical cluster analysis and factor analysis of the CORE-OM and HoNOS items. The cluster analysis shows two main clusters (1 and 2), each broken down into two further clusters ( $a$ and $b$ ). Cluster 1 features all the non-risk CORE-OM items and three of the HoNOS items ('other mental and behavioural problems', 'problems with relationships' and 'problems with depressed mood'), whereas cluster 2 brings together the CORE-OM risk items and the remaining HoNOS items. Cluster 1a includes items mainly from the CORE-OM Problems sub-scale together with the three HoNOS items; cluster $1 \mathrm{~b}$ includes items mainly from the CORE-OM Wellbeing and Functioning subscales. Cluster 2a includes the CORE-OM risk items and two HoNOS risk items ('non-accidental self-injury' and 'overactive, aggressive, disruptive or agitated behaviour'), with the self-injury HoNOS item being closely related to the four CORE-OM 'risk to self' items, and the aggression HoNOS item being closely related to the two CORE-OM 'risk to others' items. Cluster $2 \mathrm{~b}$ contains the remaining HoNOS items.

The results of the factor analysis echo those of the cluster analysis, with some minor differences. A HoNOS item ('problems with relationships') grouped with the CORE-OM non-risk items by the cluster analysis is now grouped closer to the other HoNOS items. The CORE-OM risk to self item 34 ('I have hurt myself physically. ..') is closer to the risk to others items in the factor analysis than to the remaining risk to self items.

\section{Discussion}

The findings that the HoNOS and CORE-OM total scores share $50 \%$ of the variance and that their respective risk items (CORE-OM risk sub-scale and HoNOS behavioural problems sub-scale) have $57 \%$ common variance suggest that both these widely used measures are identifying a common component of clients presenting with severe problems. Interestingly, the risk scale of the CORE-OM, comprising only six items, yielded as good if not better associations with the overall HoNOS and its behavioural scale than the CORE-OM total. Hence, the CORE-OM risk scale might prove a cost-efficient means of quickly obtaining clinically meaningful data.

The cluster 1a grouping of three HoNOS items, 'other mental and behavioural problems', 'problems with relationships' and 'problems with depressed mood', with nine of the CORE-OM non-risk items reinforces the finding that these three HoNOS items are those that have shown 
Table 1. Results of hierarchical cluster analysis and maximum likelihood factor analysis for CORE-OM and HoNOS items

\begin{tabular}{|c|c|c|c|c|c|}
\hline Questionnaire & Item & Sub-scale & Content & $\begin{array}{l}\text { HCA (Ward's } \\
\text { method) cluster }\end{array}$ & $\begin{array}{c}\text { MLFA factor } \\
\text { (oblique) } \\
\geqslant 0.25\end{array}$ \\
\hline CORE-OM & $\mathrm{C} 13$ & Problems & $\begin{array}{l}\text { I have been disturbed by unwanted thoughts and } \\
\text { feelings }\end{array}$ & 1a & 1 \\
\hline CORE-OM & $\mathrm{C} 11$ & Problems & $\begin{array}{l}\text { Tension and anxiety have prevented me doing } \\
\text { important things }\end{array}$ & $1 a$ & 1 \\
\hline CORE-OM & $\mathrm{C} 28$ & Problems & $\begin{array}{l}\text { Unwanted images or memories have been } \\
\text { distressing me }\end{array}$ & $1 a$ & 1 \\
\hline CORE-OM & C15 & Problems & I have felt panic or terror & $1 \mathrm{a}$ & 1 \\
\hline CORE-OM & $\mathrm{CO} 2$ & Problems & I have felt tense, anxious or nervous & $1 a$ & 1 \\
\hline CORE-OM & C08 & Problems & $\begin{array}{l}\text { I have been troubled by aches, pains or other } \\
\text { physical problems }\end{array}$ & $1 a$ & 1 \\
\hline CORE-OM & $\mathrm{C} 18$ & Problems & $\begin{array}{l}\text { I have had difficulty getting to sleep or staying } \\
\text { asleep }\end{array}$ & $1 a$ & 1 \\
\hline HONOS & HC8 & C & Other mental and behavioural problems & $1 \mathrm{a}$ & 1 \\
\hline CORE-OM & C05 & Problems & I have felt totally lacking in energy and enthusiasm & $1 a$ & 3 \\
\hline CORE-OM & $\mathrm{C} 21$ & Functioning & I have been able to do most things I needed to do & $1 \mathrm{a}$ & 3 \\
\hline HONOS & HD9 & $\mathrm{D}$ & Problems with relationships & $1 \mathrm{a}$ & 4 \\
\hline HoNOS & $\mathrm{HC} 7$ & $\mathrm{C}$ & Problems with depressed mood & $1 a$ & - \\
\hline CORE-OM & C33 & Functioning & I have felt humiliated or shamed by other people & $1 b$ & 1 \\
\hline CORE-OM & C29 & Functioning & I have been irritable when with other people & $1 \mathrm{~b}$ & 1 \\
\hline CORE-OM & $\mathrm{C} 17$ & Wellbeing & I have felt overwhelmed by my problems & $1 b$ & 1 \\
\hline CORE-OM & C14 & Wellbeing & I have felt like crying & $1 \mathrm{~b}$ & 1 \\
\hline CORE-OM & $\mathrm{C} 20$ & Problems & $\begin{array}{l}\text { My problems have been impossible to put to one } \\
\text { side }\end{array}$ & $1 b$ & 1 \\
\hline CORE-OM & $\mathrm{C} 25$ & Functioning & I have felt criticised by other people & $1 \mathrm{~b}$ & 1 \\
\hline CORE-OM & C30 & Problems & $\begin{array}{l}\text { I have thought I am to blame for my problems and } \\
\text { difficulties }\end{array}$ & $1 b$ & 1 \\
\hline CORE-OM & $\mathrm{C} 01$ & Functioning & I have felt terribly alone and isolated & $1 b$ & 2 \\
\hline CORE-OM & $\mathrm{C} 23$ & Problems & I have felt despairing or hopeless & $1 b$ & 3 \\
\hline CORE-OM & $\mathrm{C} 27$ & Problems & I have felt unhappy & $1 b$ & 3 \\
\hline CORE-OM & $\mathrm{CO7}$ & Functioning & I have felt able to cope when things go wrong & $1 b$ & 3 \\
\hline CORE-OM & C26 & Functioning & I have thought I have no friends & $1 b$ & 3 \\
\hline CORE-OM & $\mathrm{C} 12$ & Functioning & I have been happy with the things I have done & $1 \mathrm{~b}$ & 3 \\
\hline CORE-OM & $\mathrm{C} 32$ & Functioning & I have achieved the things I wanted to & $1 b$ & 3 \\
\hline CORE-OM & C04 & Wellbeing & I have felt OK about myself & $1 \mathrm{~b}$ & 3 \\
\hline CORE-OM & C31 & Wellbeing & I have felt optimistic about my future & $1 \mathrm{~b}$ & 3 \\
\hline CORE-OM & $\mathrm{C03}$ & Functioning & $\begin{array}{l}\text { I have felt I have someone to turn to for support } \\
\text { when needed }\end{array}$ & $1 \mathrm{~b}$ & 3 \\
\hline CORE-OM & C19 & Functioning & I have felt warmth or affection for someone & $1 \mathrm{~b}$ & 3 \\
\hline CORE-OM & $\mathrm{C} 10$ & Functioning & Talking to people has felt too much for me & $1 \mathrm{~b}$ & 3 \\
\hline CORE-OM & RS09 & Risk to self & I have thought of hurting myself & $2 a$ & 2 \\
\hline HoNOS & HA2 & A & Non-accidental self-injury & $2 a$ & 2 \\
\hline CORE-OM & RS16 & Risk to self & I made plans to end my life & $2 a$ & 2 \\
\hline CORE-OM & RS24 & Risk to self & I have thought it would be better if I were dead & $2 a$ & 2 \\
\hline CORE-OM & RS34 & Risk to self & $\begin{array}{l}\text { I have hurt myself physically or taken dangerous } \\
\text { risks with my health }\end{array}$ & $2 a$ & 4 \\
\hline HoNOS & HA1 & A & Overactive, aggressive, disruptive or agitated behaviour & $2 a$ & 4 \\
\hline CORE-OM & $\mathrm{RO} 22$ & Risk to others & I have threatened or intimidated another person & $2 a$ & 4 \\
\hline CORE-OM & RO06 & Risk to others & I have been physically violent to others & $2 a$ & 4 \\
\hline HoNOS & HA3 & A & Problem drinking or drug-taking & $2 b$ & 4 \\
\hline HoNOS & HD11 & $\mathrm{D}$ & Problems with living conditions & $2 b$ & 4 \\
\hline HoNOS & HC6 & $\mathrm{C}$ & Problems with hallucinations and delusions & $2 b$ & 4 \\
\hline HoNOS & HB4 & $\mathrm{B}$ & Cognitive problems & $2 b$ & 4 \\
\hline HoNOS & HD12 & $\mathrm{D}$ & Problems with occupation and activities & $2 b$ & 4 \\
\hline HONOS & HD10 & $\mathrm{D}$ & Problems with activities of daily living & $2 b$ & 4 \\
\hline HoNOS & HB5 & B & Physical illness or disability problems & $2 b$ & - \\
\hline
\end{tabular}

CORE-OM, Clinical Outcomes in Routine Evaluation - Outcome Measure; HCA, hierarchical cluster analysis; HoNOS, Health of the Nation Outcome Scale; MLFA, maximum likelihood factor analysis. 
evidence of being sensitive to change following psychological therapies (Audin et al, 2001).

The HoNOS is the recommended measure for clients

original

papers with severe and enduring problems (Fonagy et al, 2004). In circumstances where a self-report measure is appropriate, for example where staff trained in the use of HoNOS are not available, CORE-OM can provide information relating to some of the key domains, particularly risk.

\section{Declaration of interest}

M.B. is a member of the Board of Trustees of the CORE System Trust.

\section{References}

AUDIN, K., MARGISON, F. R., MELLOR CLARK, J., et al (2001) Value of HoNOS in assessing patient change in NHS psychotherapy and psychological treatment services. British Journal of Psychiatry, 178, 561-566.

BARKHAM, M., MARGISON, F., LEACH, C., et al (2001) Service profiling and outcomes benchmarking using the CORE-OM: towards practice-based evidence in the psychological therapies. Journal of Consulting and Clinical Psychology, 69, 184-196.

BARKHAM, M., GILBERT, N., CONNELL, J., et al (2005) Suitability and utility of the CORE-OM and CORE-A for assessing severity of presenting problems in psychological therapy services based in primary and secondary care settings. British Journal of Psychiatry, 186, 239-246.
BECK, A.T. \& STEER, R. A. (1993) Manual for the Beck Depression Inventory. San Antonio,TX: Psychologica Corporation.

ENDICOTT, J., SPITZER, R. L., FLEISS, J. L., et al (1976) The Global Assessment Scale. Archives of General Psychiatry, 33,766-771.

EVANS, C., CONNELL, J., BARKHAM, M., et al (2002) Towards a standardised brief outcome measure: psychometric properties and utility of the CORE-OM. BritishJournal of Psychiatry, 180, 51-60.

FONAGY, P., MATTHEWS, R. \& PILLING, S. (2004) The Mental Health Outcomes Measurement Initiative: Report from the Chair of the Outcomes Reference Group. London: National Collaborating Centre for Mental Health, Department of Health.
GOLDBERG, D. P. (1978) Manual of the General Health Questionnaire. Slough: NFER/Nelson.

KAZARIAN, S. S. \& JOSEPH, L.W. (1994)

A brief scale to help identify

outpatients' level of need for

community support services. Hospital

and Community Psychiatry, $\mathbf{4 5}$,

935-937.

LEACH, C., LUCOCK, M., BARKHAM, M., et al (2005) Transforming between Beck Depression Inventory and COREOM scores in routine clinical practice. British Journal of Clinical Psychology in press.

McCLELLAND, R., TRIMBLE, P., FOX M. L., et al (1998) Validation of an outcome scale for use in adult psychiatric practice. Quality and Safety in Health Care, 9, 98-105.

NATIONAL INSTITUTE FOR MENTAL HEALTH IN ENGLAND (2002) Outcome Measures for Routine Practice in Mental Health Services. London: NIMHE (http://83.223.102.91/archivepolicy/ nsf.asp).

NATIONAL INSTITUTE FOR MENTAL HEALTH IN ENGLAND (2004) Organising and Delivering Psychological Therapies. London: NIMHE.

ORRELL, M.,YARD, P., HANDYSIDES, J., et al (1999) Validity and reliability of the
Health of the Nation Outcome Scales in psychiatric patients in the community. British Journal of Psychiatry, 174 409-412.

OVERALL, J. E. \& GORHAM, D. R. (1962) The Brief Psychiatric Rating Scale.

OZER, D. J. (1985) Correlation and the coefficient of determination. Psychological Bulletin, 97, 307-315.

REES, A., RICHARDS, A. \& SHAPIRO, D. A. (2004) Utility of the HoNOS in measuring change in a Community Mental Health Care population. Journal of Mental Health, 13, 295-304.

WARE, J. E. \& SHERBOURNE, C. D. (1990) The MOS 36-item short form health survey (SF-36): conceptual framework and item selection. Medical Care, 30, 473-483.

WING, J. K., BEEVOR, A. S., CURTIS,

R. H., et al (1998) Health of the Nation Outcome Scales (HoNOS): research and development. British Journal of Psychiatry, 172, 11-18.

WYKES, T. \& STURT, E. (1986) The measurement of social behaviour in psychiatric patients: an assessment of the reliability and validity of the SBS schedule. British Journal of Psychiatry, 148, 1-11. Psychological Reports, 10,799-812.

*Chris Leach Consultant Clinical Psychologist, South West Yorkshire Menta Health NHS Trust and University of Huddersfield, Department of Psychological Services, Calderdale Royal Hospital, Halifax HX3 OPW, e-mail: chris.leach@ cht.nhs.uk, Mike Lucock Director of Psychological Research, SouthWest Yorkshire Mental Health NHS Trust and University of Huddersfield, Michael Barkham Director, Psychological Therapies Research Centre, University of Leeds, Rachael Noble Assistant Psychologist, Linda Clarke Manager, PLATT Team, Steve Iveson Director of Adult Psychological Therapies Service, SouthWest Yorkshire Mental Health NHS Trust 